\title{
REVIEW
}

\section{Echocardiographic differentiation of pathological and physiological left ventricular hypertrophy}

\author{
D J R Hildick-Smith, L M Shapiro
}

Left ventricular hypertrophy is a serious condition, strongly associated with the development of coronary artery disease, cerebrovascular disease, cardiac failure, sudden cardiac death, and overall mortality. ${ }^{1-4}$ In addition, regression of left ventricular hypertrophy is associated with reduction in all cause and cardiovascular mortality. The existence, therefore, of left ventricular hypertrophy in apparently healthy people has generated considerable interest ever since its initial description. ${ }^{5}$ Debate has centred on two major issues. The first concerns the nature of left ventricular hypertrophy of athleticism: is it simply a physiological response to periodic myocardial loading or does it have a pathological component and therefore carry implications for long term prognosis? The second concerns the diagnosis of left ventricular hypertrophy of athleticism: is it possible to differentiate with confidence physiological left ventricular hypertrophy from pathological conditions?

\section{Physiology and pathology-a continuum or separate entities?}

Cardiac enlargement in response to long term training was first described a century ago and was considered to be a purely physiological response. ${ }^{5}$ Much later, the theory was developed that left ventricular hypertrophy is part of a continuum and that transition from the early (physiological) to late (pathological) forms can occur. ${ }^{6}$ Certainly there are a few studies in veteran athletes, which raise some questions about long term cardiovascular well being, ${ }^{78}$ but these are heavily outweighed by the volume of studies showing cardiovascular health and longevity in athletes. ${ }^{9-11}$ The discovery that $A C E$ genotype influences the degree of development of left ventricular hypertrophy in athletes complicates the issue $e^{12}$ and suggests that the development of left ventricular hypertrophy is multifactorial, but most authors continue to believe that athletic left ventricular hypertrophy is a purely physiological condition. ${ }^{14-18}$

Papworth Hospital, Cambridge CB3 8RE, UK

D J R Hildick-Smith L M Shapiro

Correspondence to: Dr Hildick-Smith david.hildick-smith@ papworth-tr.anglox.nhs.uk

Accepted 13 February 2001
Fear of litigation under these circumstances and the responsibilities of screening programmes before competitive athletic participation are certainly two of the driving forces behind the continuation of this controversy. Differentiation of the physiological from the pathological is straightforward in the vast majority of cases and requires only simple echocardiographic measurements (fig 1).

\section{LEFT VENTRICULAR WALL THICKNESS}

Left ventricular wall thickness is the single most important defining characteristic separating physiological from pathological left ventricular hypertrophy. Athletic training increases both interventricular septal thickness and posterior wall thickness, but the increase averages only $10-15 \%$, reflecting an absolute increase in wall thickness of about only $1 \mathrm{~mm} .{ }^{19}$ Although there is some variation in study data, the largest and most comprehensive survey of elite athletes showed that only $2 \%$ develop an interventricular septal thickness $\geqslant 13 \mathrm{~mm} \cdot{ }^{20}$ As such, the proportion of athletes in whom there is genuine suspicion of pathological hypertrophy after simple $M$ mode and cross sectional (two dimensional) echocardiography is small.

The septal to posterior wall thickness ratio is within normal limits $(\leqslant 1.3)$ in the vast majority of athletes, ${ }^{19}$ though occasionally asymmetry of hypertrophy is seen and may initially

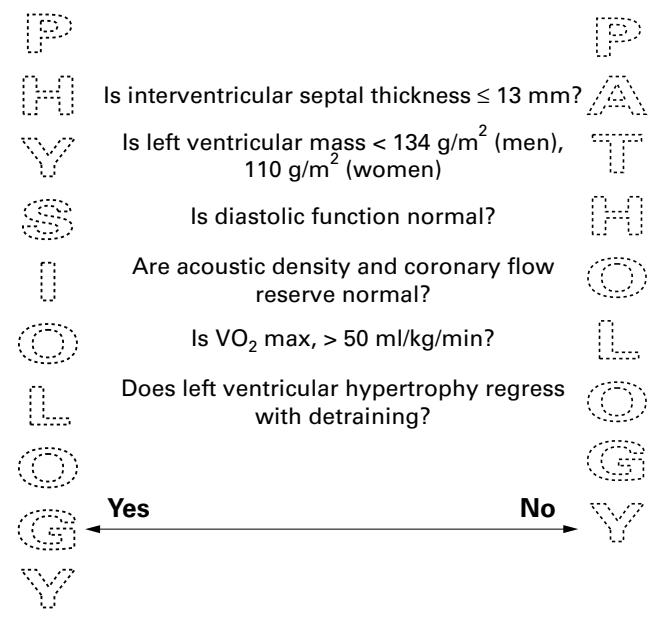

Figure 1 Schema for the echocardiographic differentiation of physiological and pathological left ventricular hypertrophy. 
mimic non-obstructive hypertrophic cardiomyopathy. These athletes do require more comprehensive echocardiographic assessment to enable a clear differentiation to be made.

Left ventricular wall thicknesses should be measured using $M$ mode rather than two dimensional echocardiography unless there is pronounced asymmetry. This allows calculation of left ventricular mass and left ventricular mass index according to the Penn convention. If significant asymmetry is present, however, a two dimensional technique for left ventricular mass estimation should be used. ${ }^{21}$ Left ventricular hypertrophy has in fact been clearly defined only relatively recently. ${ }^{22}$ Accurate identification of left ventricular hypertrophy therefore demands assessment of left ventricular mass index - that is, left ventricular mass divided by body surface area. If interventricular septal thickness is $\geqslant 13 \mathrm{~mm}$, then left ventricular mass index should be calculated. If the result is $>134 \mathrm{~g} / \mathrm{m}^{2}$ in men or $>110 \mathrm{~g} / \mathrm{m}^{2}$ in women, then left ventricular hypertrophy can truly be said to be present. ${ }^{23}$ This is an important point as the body surface area of athletes, depending on their particular discipline, may be considerable. Unfortunately, however, such absolute values are unable to take into account other factors that influence left ventricular mass, such as age and race.

While body surface area is an important parameter against which to gauge presence or absence of left ventricular hypertrophy, it is not the only yardstick that may be used. Taking body surface area as the denominator tends to underestimate the prevalence of left ventricular hypertrophy is patients who are obese-the greater the body surface area, the greater heart muscle mass must be to reach a critical cut off. This has led authors to suggest alternative means of scaling for left ventricular hypertrophy, for example using height alone ${ }^{24}$ or using lean body mass. ${ }^{25}{ }^{26}$ However, in athletes there is still no clear consensus on which allometric or ratio standard scaling would be the most appropriate.

The pattern of hypertrophy in athletes may be eccentric or concentric. Anaerobic strength training produces concentric left ventricular hypertrophy (in which wall thickness is increased in proportion to internal diameter) while endurance exercise results in eccentric hypertrophy (in which wall thickness is proportional to internal diastolic diameter) ${ }^{27}$ Despite the term "eccentric", this is a symmetrical process-true asymmetric left ventricular hypertrophy is encountered only rarely in athletes. ${ }^{28}$

Acoustic density is normal in athletes ${ }^{29}$ but is abnormal in hypertrophic cardiomyopathythe chief differential diagnosis. Left ventricular hypertrophy caused by hypertension may result in normal myocardial reflectivity, ${ }^{30}$ but this differential diagnosis is readily excluded with serial measurement of blood pressure.

LEFT VENTRICULAR INTERNAL DIMENSIONS

According to the law of Laplace, wall tension of a sphere is proportional to the radius of the sphere and the pressure within it. This law can be loosely extrapolated to the setting of left ventricular hypertrophy. If chronic pressure overload exists, septal and free wall thickness both increase to normalise wall stress. In volume overload, however, the increase is primarily in ventricular end diastolic dimension, with a proportional increase in septal and free wall thickness to normalise wall stress. The heart responds to most athletic disciplines in a manner similar to volume loading: increases in cavity size and wall thickness are appropriate compensatory mechanisms. In primarily isometric sports, however (such as weight lifting or shot putting), intermittent pressure overload combines with high systemic vascular resistance to produce thickening of the septum and posterior wall without significant increase in left ventricular cavity size.

Endurance athletes, in whom overload is in terms of volume rather than pressure, therefore develop dilatation of the left ventricular cavity. At rest, both end diastolic and end systolic diameters are enlarged. End diastolic dimension typically is increased by $10 \%{ }^{19}$ and this results in an overall increase in left ventricular mass. About $5 \%$ of elite athletes, however, have a diastolic diameter $\geqslant 6.0 \mathrm{~cm},{ }^{20}$ well above the upper limit of normal.

Power athletes develop thickening of the septum and posterior walls without significant dilatation of the left ventricular cavity. In these athletes it is important to calculate true left ventricular mass index to avoid making a spurious diagnosis of left ventricular hypertrophy because these athletes are often very large. Once body surface area is added into the equation, left ventricular mass index may fall below the critical cut off for left ventricular hypertrophy.

Systolic function may appear to be subnormal at rest in athletes. Increased myocardial metabolic efficiency ${ }^{31}$ and greater diastolic volume combine to minimise the requirement for systolic contraction at rest. However, studies of systolic shortening fraction-the accepted objective estimate of systolic function-have usually found this to be within normal limits. ${ }^{32} 33$ Despite this, there may occasionally be diagnostic confusion with dilated cardiomyopathy. The history of habitual and well tolerated athletic activity usually clarifies the issue but rarely an athlete may need to show improved systolic contraction either during or immediately after exercise to exclude this diagnosis.

\section{LEFT VENTRICULAR MASS}

As a result of increased wall thickness and diastolic dimension, overall left ventricular mass rises with training. In elite athletes, this increase averages $40-50 \%$ in comparison with sedentary controls. ${ }^{19}$ Left ventricular mass and more particularly mass index are the benchmarks by which left ventricular hypertrophy should be judged. Mass can be calculated at transthoracic echocardiography using either Devereux's classic $M$ mode formula ${ }^{34}$ or two dimensional estimation. ${ }^{21} \mathrm{M}$ mode is accurate in subjects without significant asymmetry of hypertrophy but when asymmetry is present two dimensional analysis should be made. ${ }^{35}$ 
Both three dimensional echocardiography and magnetic resonance imaging are able to provide accurate data on left ventricular mass and may supersede current methods that extrapolate left ventricular mass from two dimensional data. When appropriate calculations are made, true left ventricular hypertrophy is present in only about $50 \%$ of elite male athletes. ${ }^{28} 3637$ The upper limit of physiological left ventricular hypertrophy is considered to be approximately $500 \mathrm{~g}^{38}$

\section{DIASTOLIC FUNCTION}

Echocardiographic measurement of diastolic function is of paramount importance in the differentiation of physiological and pathological left ventricular hypertrophy. If doubt persists following $M$ mode and two dimensional imaging, calculation of left ventricular mass, and assessment of acoustic density, diastolic function should clarify the issue. The diastolic dysfunction that is a hallmark of pathological left ventricular hypertrophy ${ }^{39}{ }^{40}$ is notably absent in physiological hypertrophy. ${ }^{4142}$

The main echocardiographic determinants of diastolic function are early (E) diastolic filling velocity, late (A) diastolic filling velocity, their ratio (E:A ratio), and the pattern of pulmonary vein inflow. Early diastolic filling reflects postsystolic myocardial relaxation, while the atrial component reflects ventricular compliance. The majority of subjects in whom doubt may exist as to whether hypertrophy is physiological or pathological are less than 40 years old, and in these people, normal E velocity is approximately $0.8 \mathrm{~m} / \mathrm{s}$ and normal A velocity approximately $0.5 \mathrm{~m} / \mathrm{s}$, giving an E:A ratio significantly greater than 1 . In most cardiac disease, the initial abnormality of diastolic filling is in the relaxation phase. Isovolumic relaxation time is prolonged, as is the post-E wave deceleration time. Subjects capable of undertaking sufficient exercise for doubt to exist as to whether hypertrophy might be physiological or pathological are unlikely to have advanced cardiac disease, and therefore if the $\mathrm{E}: \mathrm{A}$ ratio is $<1$, the deceleration time is greater than $240 \mathrm{~ms}$, and isovolumic relaxation time is greater than $90 \mathrm{~ms}$, there should be genuine concern that pathological left ventricular hypertrophy exists. More complex patterns of diastolic dysfunction, such as pseudonormalised or restrictive filling, are unlikely to be compatible with the capacity for sustained vigorous exercise. However, if mitral flow appears normal, but pseudonormalised flow is a possibility, pulmonary venous inflow should be assessed. This can differentiate between true normal mitral inflow and pseudonormal inflow in a significant proportion of patients. ${ }^{43}$

In normal older subjects ( $>60$ years), $\mathrm{E}$ is reduced while $\mathrm{A}$ is increased and the $\mathrm{E}: \mathrm{A}$ ratio is more likely to approximate 1 . In veteran athletes, therefore, measurement of diastolic function is in general a less useful means by which to separate physiological and pathological left ventricular hypertrophy. This difficulty is illustrated by the conflicting results of studies in this population. ${ }^{75}$
DETRAINING

Detraining tends to be unpopular with athletes, who are both physically and mentally attuned to habitual exercise. However, where concern persists about possible pathology, the career of a given athlete is threatened until the situation is adequately resolved. Detraining therefore may be the only way to settle the issue.

There is no doubt that detraining results in regression of physiological left ventricular hypertrophy. ${ }^{19}{ }^{46-48}$ The same is clearly not true of pathological left ventricular hypertrophy. The period of detraining required is, fortunately, short because physiological hypertrophy regresses in a matter of weeks, irrespective of the duration of the preceding training. ${ }^{46}$

In athletes unwilling or unprepared to consider a period of detraining, which may be highly inconvenient from a career perspective and possibly even unrealistic, cardiopulmonary exercise testing may allow differentiation. ${ }^{49} 50$ In this population, hypertrophic cardiomyopathy is the chief differential diagnosis and the maximal oxygen consumption $\left(\mathrm{Vo}_{2}\right)$ capacity varies widely between the two conditions. In hypertrophic cardiomyopathy, $\mathrm{VO}_{2}$ max is usually in the region of $30 \mathrm{ml} / \mathrm{kg} / \mathrm{min},{ }^{51}$ whereas in athletes values approach $70 \mathrm{ml} / \mathrm{kg} / \mathrm{min}$. Interestingly, athletes with and without left ventricular hypertrophy have been compared by this method and have been found not to have significantly differing $\mathrm{Vo}_{2}$ max values. The authors of this particular study suggest that a $\mathrm{VO}_{2} \max$ of $>50 \mathrm{ml} / \mathrm{kg} / \mathrm{min}$, or $>20 \%$ above predicted maximum, can reliably be used to differentiate physiological left ventricular hypertrophy from hypertrophic cardiomyopathy. ${ }^{50}$

OTHER ECHOCARDIOGRAPHIC MARKERS

A number of other less sensitive or more speculative echocardiographic markers may help to differentiate the physiological from the pathological.

Left main stem, proximal right coronary artery, and distal left anterior descending coronary artery diameters are increased in elite athlete $^{52-55}$ and can readily be measured by transthoracic echocardiography. ${ }^{52}{ }^{53}$ In pathological left ventricular hypertrophy, although coronary diameter is also increased, it fails to increase in proportion to the increase in left ventricular muscle mass. ${ }^{56-58}$ Coronary vasodilatation in response to glyceryl trinitrate is proportionately greater in physiological than in pathological left ventricular hypertrophy. ${ }^{54} 5659$

Coronary flow reserve can also be assessed by transthoracic echocardiography. ${ }^{60}$ The spectral Doppler signal from the distal left anterior descending coronary artery is assessed at rest and during intravenous adenosine infusion. Athletes have an augmented coronary flow reserve-chiefly as a result of low resting coronary flow-while patients with left ventricular hypertrophy have impaired coronary flow reserve. ${ }^{59}{ }^{61-63}$ Given that the chief differential diagnosis is hypertrophic cardiomyopathy, this is a potentially useful discriminator, corroborated in one study by using positron emission tomography. ${ }^{61}$ 
Myocardial velocity gradient, a colour Doppler variable that quantifies the spatial distribution of transmyocardial velocities, is another experimental technique that shows some promise in being able to differentiate hypertrophic cardiomyopathy from physiological hypertrophy. The myocardial velocity gradient is lower in both systole and diastole in patients with hypertrophic cardiomyopathy.

OTHER IMAGING MODALITIES

Transoesophageal echocardiography has little additional information to provide in this group of patients. Athletes are often ideal echocardiographic subjects and, with the use of second harmonic imaging and contrast media if necessary, transthoracic images are optimal. Analysis of proximal coronary diameter is one area in which transoesophageal images would provide more accurate information, but the sensitivity of coronary diameter as a discriminator is low.

Positron emission tomography is chiefly of use in the assessment of coronary flow reserve. As this can be more simply assessed with adenosine transthoracic echocardiography, there is little call for positron emission tomography in the investigation of these patients.

Magnetic resonance imaging is the other most promising imaging modality for distinguishing physiological from pathological left ventricular hypertrophy. Myocardial mass, metabolism, and coronary diameter can all be accurately assessed by magnetic resonance imaging, which is becoming established as a yardstick, particularly for estimation of left ventricular mass. ${ }^{185564}$

\section{CONCLUSIONS}

Differentiation of physiological from pathological left ventricular hypertrophy is usually straightforward. Echocardiographically, interventricular septal thickness rarely exceeds $12 \mathrm{~mm}$ in athletes. In these people, other echocardiographic parameters such as left ventricular mass index, acoustic density, and diastolic function should clarify the issue. If, despite these investigations, there is still doubt, then a period of detraining is requiredphysiological hypertrophy regresses, while pathological hypertrophy does not.

1 Levy D. Clinical significance of left ventricular hypertrophy: insights from the Framingham Study. $f$ Cardiovasc Pharmacol 1991;17:S1-6.

2 Kannel WB. Left ventricular hypertrophy as a risk factor: the Framingham experience. F Hypertens Suppl 1991;9:S38 .

3 Kannel WB, Gordon T, Castelli WP, et al. Electrocardiographic left ventricular hypertrophy and risk of coronary heart disease. The Framingham study. Ann Intern Med 1970;72:813-22.

4 Kannel WB, Gordon T, Offutt D. Left ventricular hypertrophy by electrocardiogram: prevalence, incidence, and mor-
tality in the Framingham study. Ann Intern Med 1969;71: tality in the 105 .

5 Henschen S. Skilanglauf und Skiwettlauf: Eine medizinische Sport Studie. Mitt Med Klin Uppsala 1899;2:15

6 Weber KT, Clark WA, Janicki JS, et al. Physiologic versus pathologic hypertrophy and the pressure-overloaded myocardium. 7 Cardiovasc Pharmacol 1987;10:S37-50.

7 Miki T, Yokota Y, Seo T, et al. Echocardiographic findings in 104 professional cyclists with follow-up study. Am Heart $\mathcal{F}$ 1994;127:898-905.

8 Hood S, Northcote RJ. Cardiac assessment of veteran endurance athletes: a 12 year follow up study. $\mathrm{Br} \mathcal{7}$ Sports Med 1999;33:239-43.

9 Sarna S, Sahi T, Koskenvuo M, et al. Increased life expectancy of world class male athletes. Med Sci Sports Exerc 1993;25:237-44.
10 Lakka TA, Venalainen JM, Rauramaa R, et al. Relation of leisure-time physical activity and cardiorespiratory fitness to the risk of acute myocardial infarction. $N$ Engl $\mathcal{F ~ M e d ~}$ to the risk of acute

11 Sandvik L, Erikssen J, Thaulow E, et al. Physical fitness as a predictor of mortality among healthy, middle-aged Norwegian men. N Engl F Med 1993;328:533-7.

12 Montgomery HE, Clarkson P, Dollery CM, et al. Association of angiotensin-converting enzyme gene I/D polymorphism with change in left ventricular mass in response to physical training. Circulation 1997;96:741-7.

13 Montgomery HE, Marshall R, Hemingway $\mathrm{H}$, et al. Human gene for physical performance. Nature 1998;393:221-2.

14 Vaughan Williams EM. Ventricular hypertrophy: physiological mechanisms. 7 Cardiovasc Pharmacol 1986;8:S12-6.

5 George KP, Wolfe LA, Burggraf GW. The 'athletic heart syndrome'. A critical review. Sports Med 1991;11:300-30.

16 Maron BJ, Pelliccia A, Spirito P. Cardiac disease in young trained athletes: insights into methods for distinguishing athlete's heart from structural heart disease, with particular emphasis on hypertrophic cardiomyopathy. Circulation 1995;91:1596-601.

17 Maron BJ, Thompson PD, Puffer JC, et al. Cardiovascular preparticipation screening of competitive athletes: a statement for health professionals from the sudden death committee (clinical cardiology) and congenital cardiac defects committee (cardiovascular disease in the young), American Heart Association. Circulation 1996;94:850-6.

18 Pluim BM, Lamb HJ, Kayser HW, et al. Functional and metabolic evaluation of the athlete's heart by magnetic resonance imaging and dobutamine stress magnetic resonance spectroscopy. Circulation 1998;97:666-72.

19 Maron BJ. Structural features of the athlete heart as defined by echocardiography. 7 Am Coll Cardiol 1986;7:190-203.

20 Pelliccia A, Maron BJ, Spataro A, et al. The upper limit of physiologic cardiac hypertrophy in highly trained elite athetes. N Engl f Med 1991;324:295-301.

21 Schiller NB, Shah PM, Crawford M, et al. Recommendations for quantitation of the left ventricle by twodimensional echocardiography. American Society of Echocardiography committee on standards, subcommittee on quantitation of two-dimensional echocardiograms. I Am Soc Echocardiogr 1989;2:358-67.

22 Devereux RB, Lutas EM, Casale PN, et al. Standardization of M-mode echocardiographic left ventricular anatomic measurements. F Am Coll Cardiol 1984;4:1222-30.

23 Hammond IW, Devereux RB, Alderman MH, et al. The prevalence and correlates of echocardiographic left ventricular hypertrophy among employed patients with uncomplicated hypertension. $\mathcal{F}$ Am Coll Cardiol 1986;7:63950.

24 de Simone G, Daniels SR, Devereux RB, et al. Left ventricular mass and body size in normotensive children and adults: assessment of allometric relations and impact of overweight. $\mathcal{A}$ Am Coll Cardiol 1992;20:1251-60.

25 George KP, Batterham AM, Jones B. The impact of scalar variable and process on athlete-control comparisons of cardiac dimensions. Med Sci Sports Exerc 1998;30:824-30.

26 Kuch B, Hense HW, Gneiting B, et al. Body composition and prevalence of left ventricular hypertrophy. Circulation 2000;102:405-10.

27 Fagard RH. Impact of different sports and training on cardiac structure and function. Cardiol Clin 1992;10:241-56.

28 Douglas PS, O'Toole ML, Katz SE, et al. Left ventricular hypertrophy in athletes. Am f Cardiol 1997;80:1384-8.

29 Lattanzi F, Di Bello V, Picano E, et al. Normal ultrasonic myocardial reflectivity in athletes with increased left ventricular mass. A tissue characterization study. Circulation 1992;85:1828-34.

30 Gigli G, Lattanzi F, Lucarini AR, et al. Normal ultrasonic myocardial reflectivity in hypertensive patients: a tissue myocardial reflectivity in hypertensive patients: a

31 Brown MD, Davies MK, Hudlicka O. The effect of long-term bradycardia on heart microvascular supply and performance. Cell Mol Biol Res 1994;40:137-42.

32 Colan SD, Sanders SP, Borow KM. Physiologic hypertrophy: effects on left ventricular systolic mechanics in athletes. F Am Coll Cardiol 1987;9:776-83.

33 Colan SD. Mechanics of left ventricular systolic and diastolic function in physiologic hypertrophy of the athlete's heart. Cardiol Clin 1997;15:355-72.

34 Devereux RB, Reichek N. Echocardiographic determination of left ventricular mass in man: anatomic validation of the method. Circulation 1977;55:613-8.

35 Park SH, Shub C, Nobrega TP, et al. Two-dimensional echocardiographic calculation of left ventricular mass as recommended by the American Society of Echocardiography: correlation with autopsy and M-mode chocardiography. f Am Soc Echocardiogr 1996;9:119-28.

36 Fagard RH. Athlete's heart: a meta-analysis of the echocardiographic experience. Int f Sports Med 1996;17(Suppl 3): $\$ 140-4$.

37 Douglas PS, O'Toole ML, Hiller WD, et al. Left ventricular structure and function by echocardiography in ultraendurance athletes. Am f Cardiol 1986;58:805-9.

38 Pelliccia A, Maron BJ. Outer limits of the athlete's heart, the effect of gender, and relevance to the differential diagnosis
with primary cardiac diseases. Cardiol Clin 1997;15:38196.

39 Shapiro LM, McKenna WJ. Left ventricular hypertrophy: relation of structure to diastolic function in hypertension. Br Heart $\mathcal{F}$ 1984;51:637-42.

40 Shapiro LM, Gibson DG. Patterns of diastolic dysfunction in left ventricular hypertrophy. Br Heart f 1988;59:438-45. 
41 Colan SD, Sanders SP, MacPherson D, et al. Left ventricular diastolic function in elite athletes with physiologic

42 Galanti G, Comeglio M, Vinci M, et al. Echocardiographic Doppler evaluation of left ventricular diastolic function in athletes' hypertrophied hearts. Angiology 1993;44:341-6.

43 Torrecilla EG, Garcia Fernandez MA, Bueno H, et al. Pulmonary venous flow in hypertrophic cardiomyopathy as assessed by the transoesophageal approach. The additive value of pulmonary venous flow and left atrial size variables in estimating the mitral inflow pattern in hypertrophic cardiomyopathy. Eur Heart 7 1999;20:293-302

44 Yamamoto K, Wilson DJ, Canzanello VJ, et al. Left ventricular diastolic dysfunction in patients with hypertension and preserved systolic function. Mayo Clin Proc 2000;75:148-55.

45 Di Bello V, Lattanzi F, Picano E, et al. Left ventricular performance and ultrasonic myocardial quantitative reflectivformance and ultrasonic myocardial quantitative reflectivity in endurance senior athletes:

46 Martin WHd, Coyle EF, Bloomfield SA, et al. Effects of physical deconditioning after intense endurance training on left ventricular dimen

47 Pelliccia A. Outer limits of physiologic hypertrophy and relevance to the diagnosis of primary cardiac disease. Cardio Clin 1992;10:267-79.

48 Maron BJ, Pelliccia A, Spataro A, et al. Reduction in left ventricular wall thickness after deconditioning in highly trained Olympic athletes. Br Heart f 1993;69:125-8.

49 Whyte GP, Sharma S, George K, et al. Exercise gas exchange responses in the differentiation of pathologic and physiologic left ventricular hypertrophy. Med Sci Sports Exerc 1999;31:1237-41

50 Sharma S, Elliott PM, Whyte G, et al. Utility of metabolic exercise testing in distinguishing hypertrophic cardiomyopathy from physiologic left ventricular hypertrophy in athletes. 7 Am Coll Cardiol 2000;36:864-70.

51 Lele SS, Thomson HL, Seo H, et al. Exercise capacity in hypertrophic cardiomyopathy: role of stroke volume limitahypertrophic cardiomyopathy: role of stroke volume limitation, heart rate, and diast

52 Zeppilli P, Merlino B, Vannicelli R, et al. Coronary arteries and athlete's heart. Arch Mal Coeur Vaiss 1989;82(Spec No 2):89-92.
53 Pelliccia A, Spataro A, Granata M, et al. Coronary arteries in physiological hypertrophy: echocardiographic evidence of increased proximal size in elite athletes. Int $\mathrm{f}$ Sports Med 1990;11:120-6.

54 Haskell WL, Sims C, Myll J, et al. Coronary artery size and dilating capacity in ultradistance runners. Circulation 1993; 87:1076-82.

55 Zandrino F, Molinari G, Smeraldi A, et al. Magnetic resonance imaging of athlete's heart: myocardial mass, left ventricular function, and cross-sectional area of the coronary arteries. Eur Radiol 2000;10:319-25.

56 Nitenberg A, Antony I. Epicardial coronary arteries are not adequately sized in hypertensive patients. F Am Coll Cardiol $1996 ; 27: 115-23$

57 Vassalli G, Kaufmann P, Villari B, et al. Reduced epicardial coronary vasodilator capacity in patients with left ventricular hypertrophy. Circulation 1995;91:2916-23.

58 Villari B, Hess OM, Moccetti D, et al. Effect of progression of left ventricular hypertrophy on coronary artery dimensions in aortic valve disease. $f$ Am Coll Cardiol 1992;20: 1073-9.

59 Hildick-Smith DJR, Johnson PJ, Wisbey CR, et al. Coronary flow reserve is supranormal in endurance athletes: a transthoracic echocardiographic study. Heart 2000;83:383-9.

60 Hildick-Smith DJR, Shapiro LM. Potential use of transthoracic echocardiography in the assessment of coronary flow reserve. F Am Soc Echocardiogr 1999;12:590-5.

61 Radvan J, Choudhury L, Sheridan DJ, et al. Comparison of coronary vasodilator reserve in elite rowing athletes versus hypertrophic cardiomyopathy. Am f Cardiol 1997;80:16213.

62 Toraa M, Pouillard F, Merlet P, et al. Cardiac hypertrophy and coronary reserve in endurance athletes. Can $\mathcal{F} A p p l$ Physiol 1999;24:87-95.

63 Choudhury L, Rosen SD, Patel D, et al. Coronary vasodilator reserve in primary and secondary left ventricular hypertrophy. A study with positron emission tomography. Eur Heart f 1997;18:108-16.

64 Milliken MC, Stray-Gundersen J, Peshock RM, et al. Left ventricular mass as determined by magnetic resonance imaging in male endurance athletes. Am f Cardiol 1988;62: 301-5.

\section{IMAGES IN CARDIOLOGY}

\section{Aneurysm of the mid-trabecular ventricular septal defect: a morphological novelty}

A five month old infant was referred to our centre for evaluation of a systolic murmur. A two dimensional (cross sectional) Doppler echocardiogram was undertaken which showed situs solitus, atrioventricular and ventriculoarterial concordance, an intact atrial septum, a normal aortic arch, and no duct. There were multiple muscular ventricular septal defects (VSDs) in the inlet profile and the pulmonary valve was mildly stenosed.

The midtrabecular VSD was small to moderate in size and had a large aneurysm on its right ventricular size (right) which was trying to restrict the left to right shunt.

Whereas aneurysms of the ventricular septum are frequently seen in relation to the perimembranous VSDs (leaflet tissue of the tricuspid valves tries to close them), an aneurysm of a mid-trabecula muscular VSD has not, up until now, been reported in the literature-truly a morphological novelty.

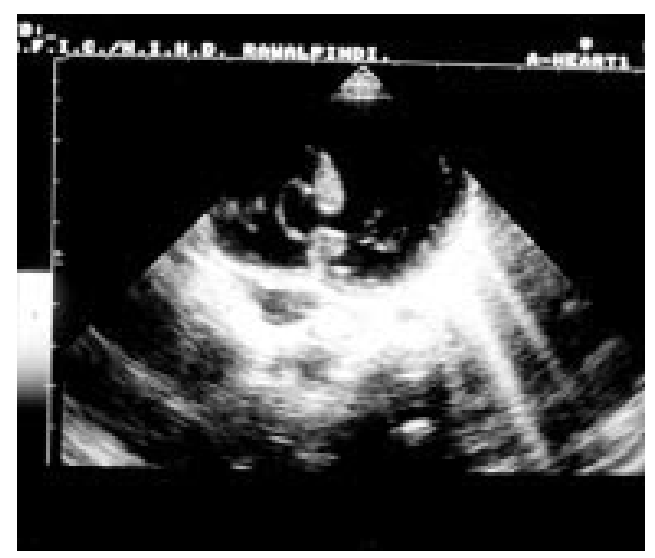

